Pedagogía y Saberes No. 46

Universidad Pedagógica Nacional

Facultad de Educación. 2017, pp. 31-44

\title{
Anna Freud y la discusión sobre la formación de los educadores
}

Artículo de investigación

Anna Freud and the discussion about teachers' training Ana Freud e a discussão sobre a formação dos professores

Carlos Jilmar Díaz-Soler*

Doctor en educación de la Universidade Estadual de Campinas (UNICAMP), profesor de la Universidad Distrital Francisco José de Caldas. E-mail: cjdiaz2014@outlook.com

Perfil ORCID: http://orcid.org/0000-0002-4566-4973 


\title{
Resumen
}

El artículo analiza la postura asumida por Anna Freud en nombre del psicoanálisis, en relación con los vínculos posibles entre psicoanálisis y educación, al tiempo que se exponen aspectos del psicoanálisis como ciencia de lo singular. En el artículo son usadas elaboraciones derivadas del programa de investigación "Teoría de 'campo' y procesos de recontextualización” (Universidad Pedagógica Nacional- Universidad Distrital Francisco José de Caldas), para analizar fenómenos relacionados con modalidades de circulación -recontextualización- de enunciados, materializados en diversos escenarios y formatos para comprender aspectos estructurales de la discusión acerca de la formación como problema central de la pedagogía.

\section{Palabras clave}

Psicoanálisis, formación, pedagogía, escuela, condición humana, estructura psíquica.

\begin{abstract}
The article shows an analysis of psychoanalysis position by Anna Freud in relation to the possible linkages between psychoanalysis and education., as some aspects of psychoanalysis as science of the singularity are stated. In this article, works derived from the research project "Field Theory and Recontextualization Processes" (Universidad Pedagógica Nacional- Universidad Distrital Francisco José de Caldas), are used to analyze phenomena related to statements traffic and re-contextualization modes which are materialized in different scenarios and formats. Then, the development of such process leads to the understanding of some structural features from the discussion regarding training as the main issue pedagogy has.
\end{abstract}

\section{Key words}

Psychoanalysis, education, pedagogy, school, human condition, psychic structures.

\section{Resumo}

El artigo analisa a postura assumida por Anna Freud, em nome da psicanálise e relacionada com os vínculos possíveis entre psicanálise e educação, ao tempo que apresenta aspectos da psicanálise como ciência do singular. No artigo são usadas elaborações derivadas do programa de pesquisa "Teoria do campo e processos de recontextualização" (Universidade Pedagógica Nacional - Universidade Distrital 'Francisco José de Caldas') para analisar fenômenos relacionados às modalidades de circulação -recontextualização- de enunciados, materializados em diversos cenários e formatos e que permitem compreender aspectos estruturais da discussão sobre a formação como problema central da pedagogia.

\section{Palavras chave}

Psicanálise, Formação, Pedagogia, Escola, Condição Humana, Estrutura Psíquica. 
Vano sería pretender narrar a un maestro cuestiones relativas a la conducta escolar. En su trabajo diario pasa por sus manos tal cúmulo de material que, quiera o no advertirlo, llega a conocer con la mayor precisión la gama completa de las variadas manifestaciones que median: desde el niño física y mentalmente defectuoso, hosco, intimidado, mentiroso y maltratado, hasta el brutal, agresivo y criminal [...] Pero esa misma situación práctica que le confiere al maestro tan cabal conocimiento en el campo de los hechos educacionales, asimismo le presenta inconvenientes, pues, trabaje en el jardín de infantes, con escolares pequeños o mayores, encuéntrase incesantemente sometido a la imperiosa necesidad de actuar. La vida y la actividad de los grupos escolares exígele constante intervención: debe reprender, prohibir y conservar

la disciplina; mantener al niño en actividad, educarlo e instruirlo. Malamente cumplirá su misión pedagógica si de pronto se le ocurriera retirarse a la posición de pasivo observador. De ahí que, si bien su profesión oblígale a reconocer a primera vista un sinnúmero de manifestaciones de

la vida infantil, que le impide disponer de tiempo,

su vocación está en ordenar esos hechos que ve desarrollarse ante sus ojos, y remontarse hasta las causas de las relaciones infantiles, no obstante su misión de influir sobre ellas.

Anna Freud [1930]

\section{Introducción}

$\mathrm{A}$ la consolidación del psicoanálisis contribuyen psicoanalistas, como Anna Freud, que dedican sus esfuerzos a discutir su vínculo con la educación. Al pasar a ser el niño fuente de interés para la indagación psicoanalítica, los investigadores relacionados con la educación y la pedagogía cifraron alguna expectativa en torno al empeño psicoanalítico. El psicoanálisis se consolida precisamente durante el periodo histórico en el que se produce la infancia y en el cual la escuela gana sentido social y político. Las manifestaciones del aparato psíquico en el escenario de la escuela, que se expresa de formas variadas (olvidos, apatías, inhibiciones o dificultades relacionadas con el saber, indisciplina, miedos, angustias, fobias o agresiones, por ejemplo), al configurar formas no deseadas por el aparato educativo se constituyen, por ende, en fuentes de inquietud, tanto para los educadores como para los psicoanalistas. Este es justamente el horizonte de trabajo para Anna Freud, justificado dada la importancia que adquiere la escuela moderna y, en ella, la infancia; novedoso encuentro que continúa suscitando un cúmulo de inquietudes.
Una intensa preocupación se suscitó hacia finales del siglo XIX en torno a las manifestaciones que se evidenciaron en los individuos por efecto de los cambios en la sociedad. Más aún, se llevó a cabo una fuerte discusión con respecto a los inveterados procesos relacionados con la educación. La pregunta por el sujeto $\mathrm{y}$, en consecuencia, por el saber sobre lo humano, en el marco de los discursos de la ciencia, cobraba renovada relevancia; en ella se venían tramitando las inquietudes en torno a la civilización: sus fines, la forma que debería asumir y los contenidos que se habrían de enseñar. Mientras tanto, escolarizar la población se hizo políticamente necesario.

La preocupación de una reforma política y moral de la sociedad se articuló a la moderna pedagogía que, a su vez, apuntaló su perspectiva desde el desarrollo como ideal. Su discusión enfrentó las novedades de la época, tomando del prestigio de las llamadas ciencias modernas -en ellas, también, ciertos desarrollos de las modernas psicología y sociología- elementos que contribuyeran a avalar su anhelado propósito, cuyo horizonte prometía bienestar, igualdad y progreso. Marco de resonancia para los discursos que alimentan las discusiones que relacionamos con la educación y la pedagogía, el cual también contribuyó a poner en funcionamiento un aparato educativo y, mediante su operación, materializar exigencias políticas tendientes a la consecución de resultados, tanto en sus funciones masificantes como en las individualizantes (Saldarriaga, 2000): por un lado cohesión social, moralización de la población, y, por otro, reclamo de efectivo aprendizaje, por ejemplo, gracias a los procesos de escolarización. El aparato escolar permitió materializar: (1) la masiva escolarización de los niños, (2) el fortalecimiento de su vínculo con los Estados nacionales, (3) la instalación de un amplio proceso de enseñanza de las ciencias, y (4) la instauración de procesos formales de formación de maestros. Este periodo histórico, al materializar el funcionamiento de un aparato escolar, posibilitó, además, que el debate político ganara relevancia: no solo en torno al reconocimiento y al cuidado de la infancia, sino también, acerca del estatuto con el que habría de comprenderse y, en este marco, aquellos debates en torno a la orientación que deben asumir los procesos de formación de profesores.

Como se destaca en el epígrafe, Anna Freud participó del mencionado debate, señalando que los maestros, en el marco de su práctica pedagógica, poseen una variada experiencia y, dada la particularidad que encarna su oficio, se encuentran incesantemente sometidos a la imperiosa necesidad de actuar, de intervenir: mantener al niño en actividad, educarlo e instruirlo; reprender, prohibir y conservar la disciplina, 
por ejemplo. Pero no solamente de intervención está hecha la práctica pedagógica, señala Anna Freud; además, es necesario un trabajo que les posibilite ordenar esos hechos que ven desarrollarse ante sus ojos y ocuparse, también, en un proceso de intelección de dichos fenómenos, con la pretensión de organizar y entender el sentido de ese actuar.

Dos discusiones asume Anna Freud, no claramente distinguibles en su obra: la primera, relacionada con la especificidad del psicoanálisis, su perspectiva en la clínica (el trabajo con la palabra, la transferencia y la interpretación), aspecto central en su sostenida elaboración conceptual.Y, relacionada con su esfuerzo tendiente a presentar a los profesores la elaboración que desarrolla el psicoanálisis sobre la condición humana, la segunda discusión tiende a presentar posibles aplicaciones a la dinámica escolar. En consecuencia, al buscar transmitir a los profesores su discusión sobre el psicoanálisis, directamente lo conecta con la educación.

Sabemos hoy, sin embargo, que quien desee comprender las relaciones entre el psicoanálisis y la educación requiere, también, elaborar distinciones entre, por un lado la teoría y, por otro, sus posibles aplicaciones. Entre la teoría y su aplicación hay un abismo: a cada uno de estos campos les subyace una particular materialización de la subjetividad, sendos horizontes configurados, tanto por su propio objeto, como por intereses particulares. Por ello, una relación directa, expedita entre uno y otro campo no es posible; pensar en la aplicación de una teoría es enfrentarse a un problema epistemológico. Se hace necesario, en consecuencia, la construcción de los puentes de rigor, de lo contrario, el potencial heurístico de la teoría desaparece y las posibles aplicaciones a la práctica, por ejemplo, se extravían en la vorágine de la acción educativa.

Conflictivas, entonces, son las relaciones entre el psicoanálisis y la pedagogía. Cada una presenta su propio horizonte y, si deseamos comprender sus posibles vínculos, será necesario establecer, también, sendas especificidades. Es decir, ponerlas en relación sería posible solo a condición de saberse inmiscuido en la puntual lógica de cada una. Para el psicoanálisis, por ejemplo, la apuesta está centrada en la elucidación que el sujeto pueda elaborar de su singularidad, en el marco del dispositivo analítico y su decisión de hacer algo con ello. La elaboración conceptual que se produce como efecto contribuye a comprender la condición humana; marco analítico que resulta propicio, también, para sostener un fecundo diálogo entre el psicoanálisis y la ciencia. Por su parte, la educación centra sus esfuerzos en el amplio espectro tendiente a configurar escenarios para generar, no solo procesos para el cuidado, sino también, para propiciar espacios de identificación con la cultura que, en el marco de la selección de saberes por enseñar, por un lado $\mathrm{y}$, por otro, mediante la organización de procesos de enseñanza de los saberes, generan, en todo caso, determinadas condiciones de posibilidad.

Inveterado dispositivo -la educación- que requeriría esfuerzos de intelección, tanto de su funcionamiento como, también, de intelección de aquellas dificultades u obstáculos con los que se depara la escuela en sus propósitos. Marco propicio, como es posible entrever, para sostener un fecundo debate entre el moderno horizonte propuesto por la ciencia a los procesos tendientes a la enseñanza, por un lado y, por otro, la discusión que, en torno a la condición humana, propone el psicoanálisis. Anna Freud recoge, en consecuencia, los esfuerzos analíticos que desde el psicoanálisis se llevan a cabo en torno a la comprensión de la condición humana y, desde allí, interroga su posible aplicación a la práctica pedagógica.

\section{La transmisión: problema para la formación de los profesores}

Anna Freud participa de un debate prolongado en el tiempo, en cuyo horizonte está planteado el problema de los vínculos -intersección y desencuentros- entre civilización y educación. Su interés está centrado en la pregunta por el sujeto y sus vínculos con la cultura y, allí, discute la forma en la que se llevan a cabo los procesos educativos. Sus esfuerzos están dirigidos al particular asunto de la formación de los profesores, específicamente en lo relacionado con el incómodo problema de la comprensión de los principios con los que opera el educador; con ello se pregunta, también, por aquellas estrategias que posibilitarían potenciar el acto educativo. Este marco de discusión contribuye a la identificación de aquellas dificultades propias del oficio de enseñar.

Así, inscrita en la perspectiva inaugurada por el psicoanálisis, la discusión propuesta por Anna Freud está dirigida al pedagogo: "Más al que cuida al niño, por ejemplo, en el jardín de infantes, que al que se ocupará de hacerle asimilar contenidos intelectuales" (p. 11). Insta, en consecuencia,

[...] al educador, deseoso de profundizar su saber acerca de los fundamentos psíquicos de las manifestaciones infantiles, a que procure comprender sus rasgos característicos y explicarse el lento desarrollo que siguen en cada caso, acudiendo para ello a la nueva ciencia del psicoanálisis. (p. 16). 
Sigmund Freud (1856-1939) se preguntó por la educación; destinó párrafos y comentarios al respecto. Sin embargo una paradoja se nos presenta: si bien Freud señaló que los asuntos relacionados con la educación y la pedagogía revisten especial importancia y serían "el principal motivo de aplicación del psicoanálisis" (1932, p. 135), no dedicó ningún texto a la educación; en su obra encontramos algunas elaboraciones al respecto en textos dirigidos a su discusión central: el oficio en la clínica. Su elaborada discusión contribuye, no obstante, a precisar asuntos relacionados con la formación, la educación y la pedagogía (Bustamante, 2013; Lajonquière, 1999, 2011; Millot, 1979).

Ya en 1913, Sigmund Freud escribía: “Ojalá que la aplicación del psicoanálisis al servicio de la educación llene pronto las esperanzas que educadores y psicoanalistas tienen derecho a poner en ella!" (p. 353). Para este momento de su elaboración conceptual sugiere, con cierto optimismo, que el esclarecimiento de los educadores mediante el psicoanálisis ayudaría a prevenir y potenciar los asuntos relacionados con la educación y la pedagogía; elaboración que contrasta con una toma de posición en 1932, cuando nuevamente se refiere a la educación:

[...] la educación tiene que inhibir, prohibir, sofocar y en efecto es lo que todas las épocas han procurado hacer abundantemente. Ahora bien; por el análisis hemos sabido que esa misma sofocación de lo pulsional conlleva el peligro de contraer neurosis [...] Entonces la educación tiene que buscar su senda entre su Escila de la permisión y la Caribdis de la denegación (frustración). (p. 138).

Con estas líneas podemos comprender tanto su postura como las premisas asumidas frente a los asuntos relacionados con la educación:

1. Todas las épocas necesitan abundantes procesos tendientes a inhibir, prohibir, sofocar. A escala estructural la educación es la misma: dada la condición humana, educar es necesario; en consecuencia, puntuales periodos históricos materializan formas particulares de inhibir, prohibir, sofocar.

2. Sofocar lo pulsional produce efectos: inevitable resultado, dada la condición humana. Es posible colegir, en consecuencia, que su discusión apunta a la intelección de la infancia no como un periodo de irrealización de la conducta humana. Comprender la infancia estaría más allá del simple espectro cronológico; apunta a plantear, incluso en la infancia, un sujeto de pleno ejercicio.

Ergo,

3. Los procesos propios de la educación, junto con aquellos desarrollados en escenarios de escolariza- ción, "quieren cuidar que de ciertas disposiciones [estructura del aparato psíquico] einclinaciones del niño no salga nada dañino para el individuo o para la sociedad" (Sigmund Freud, 1913, pp. 351-352). Abrir un camino entre la permisión y la denegación implica afrontar el inevitable riesgo de transitar entre el horizonte de las exigencias propias de escenarios de culturización, que se ejercen y que pesan sobre el proceso de estructuración del sujeto, por una parte, pero, por otra, por aquellas afrentas que el individuo puede infligir a la sociedad, mediante la búsqueda de ciertas satisfacciones que podrían poner en riego a la misma sociedad.

Postura y premisas que acicatean e instan a trabajar en pos de precisar asuntos estructurales a una discusión sobre lo educativo, que merece lugar en el análisis pedagógico, dado que si aquello que relacionamos con la escuela posibilita dar trámite a la condición humana, entonces, será necesario elucidar un esquema que permita comprender la condición humana y que contribuya, a su vez, a precisar las relaciones posibles con los objetos ofrecidos por la cultura, específicamente aquellos que relacionamos con el saber, ya que, como señala Sigmund Freud (1929)

Buena parte de la brega de la humanidad gira en torno de una tarea: hallar un equilibrio acorde a afines, vale decir, dispensador de felicidad, entre esas demandas individuales y las exigencias culturales de la masa; y uno de los problemas que atañen a su destino es saber si mediante determinada configuración cultural ese equilibrio puede alcanzarse o si el conflicto es insalvable. (p. 94).

Permisión y denegación constituyen, en consecuencia, el ineludible horizonte de trabajo en la escuela. Y si la escuela es una de las ofertas que la sociedad presenta a los sujetos, entonces: ¿cómo dar trámite a esa ambigüedad y concitar, así, una decisión en el sujeto para trabajar tras lo deseado? La escuela se podría pensar, en consecuencia, como una específica formación histórica incorporada a la misma condición humana y no, como parece acontecer hoy, como uno más de aquellos dispositivos que cumplen ciertos propósitos sociales (cuidar, defender la infancia, alimentar, moralizar la población, brindar pautas de comportamiento, civilizar, proponer fuentes de identificación, dosificar conocimientos, entre otros).

Ante la pregunta por la infancia, el debate naturaleza versus cultura se tornó obligatorio para los pedagogos. Plantear que el hombre es un animal político o un animal que habla es plantear que, en la humanidad, la naturaleza fue reemplazada por la cultura. Sigmund Freud recoge la preocupación de algunos filósofos que ya afirmaban que el hombre es un animal no natural, 
al calificarlo como animal afectivo, con lo cual denota la desnaturalización del animal humano (Miller, 1988 p. 284).

Humanos y animales viven cronologías diferentes. El animal, desde el momento de nacer, ya es. Situación incomparable con la de las crías humanas: ellas no son al momento de su nacimiento; podrían llegar a ser si las condiciones de posibilidad para ello lo permiten. Un intricado proceso les espera, uno por uno, para insertarse en el mundo humano.

Comprender la radical distinción entre el mundo animal y el mundo humano implica, en consecuencia, interrogarse por el particular funcionamiento de la estructura misma del aparato psíquico. Para el mundo animal, por ejemplo, sabemos que sus límites están en el marco de un saber instintivo, al que se aúna cierto saber adquirido y cuyo horizonte está dado, en todo caso, por el imperativo de la sobrevivencia y la reproducción como individuos, asuntos que garantizarían la continuidad de la especie. En consecuencia, estímulos y sentidos están articulados: si no se presenta el estímulo, no hay despliegue de la conducta; la conducta puede ser desplegada si, y solo si, el estímulo aparece. Cada especie responde a ciertos estímulos que, a su vez, son indiferentes para otras especies.

El mundo humano, en contraste, se caracteriza porque "a cada función de la naturaleza le damos un significado cultural" (Miller, 1988). La convención es regla. Para el psicoanálisis el ser humano no es un ser natural. Por eso es posible percibir la variabilidad de las culturas y reseñar las transformaciones históricas. Enredada como lenguaje, por ejemplo, la sexualidad humana, sin objeto, está sometida a las vicisitudes de vínculos soportados en invenciones simbólicas. La sexualidad humana no funciona como lo hace el comportamiento sexual animal. Es posible deducir que el esfuerzo de Sigmund Freud permite desentrañar la particularidad de la modalidad de satisfacción del sujeto, que no se realiza como en los animales; el humano, debido a la inmersión en el lenguaje, no sigue las leyes de la naturaleza; él es un ser desnaturalizado: por hablar, se ha apartado de sus condiciones naturales y no está sometido a las leyes de la naturaleza.

Sigmund Freud encuentra que el sujeto es una ruptura con eso que hay de animal en todo ser humano, pues la pulsión es la desnaturalización del instinto biológico. No implica que lo biológico, que el organismo, quede abolido; Freud no reduce el sujeto ni a lo biológico, ni a lo consciente. La novedad que presenta entonces la discusión desde el psicoanálisis señala hacia una particular disposición del aparato (estructura) psíquico: las instancias que lo constituyen y su particular manera de funcionar. Así, al presentar un sujeto en el que se manifiestan asuntos como olvidos, inhibiciones, angustias, miedos, sueños, equívocos, asuntos relacionados con el deseo... efectos todos del funcionamiento de su aparato psíquico, lo inconsciente se torna pregunta, motor para su investigación.

En su trabajo, Anna Freud recoge la elaboración que, desde una novedosa práctica clínica, realizó su padre, Sigmund Freud. Él, mediante el análisis de las formaciones discursivas producidas en el marco del dispositivo analítico, inauguró un nuevo método de exploración, tratamiento y conceptualización de los fenómenos psíquicos, al introducir los conceptos de conciencia e inconsciente, apuntando, con ello, al debate sobre lo humano -su especificidad y su tratamiento- mediante la paciente elaboración de saber sobre su práctica clínica, fundamental como referente para el psicoanálisis.

Perspectiva analítica desde la cual Anna Freud busca presentar a los educadores los fundamentos de una novedosa discusión sobre lo humano; con ello, busca mitigar las angustias que manifiestan los educadores frente a los problemas que suscita la escolarización de los niños.

\section{Anna Freud señala que}

[...] en múltiples aspectos, este pequeño ser que tenemos ante nosotros se parece extraordinariamente a un animalito recién nacido, con la única diferencia de que su situación no es tan favorable como la de éste [...] Con la criatura humana no ocurre lo mismo: durante un año por lo menos es tan fuerte su dependencia de la madre que sucumbiría en el preciso momento en que ella retirase su protección. Pero aun superando ese año de lactancia no alcanza su independencia, pues todavía no sabe procurar su alimento, mantenerse y protegerse o defenderse de los posibles peligros exteriores. He sabido que para alcanzar completa autonomía, respecto de la protección del adulto y llegar a serlo, a su vez, requiere casi tres lustros. (pp. 22-23).

Destaca que la criatura humana es diferente; no obstante, no logra precisar la diferencia. Basándose en la certeza que proviene de la observación, de la mano de cierta idea de cronología, asume como plausible la idea de sucesivas transformaciones (lactancia, protección, escolarización y camino hacia la autonomía, luego de tres lustros). Con la certeza puesta en el mundo de lo sensible, su esfuerzo de distinción, es decir de caracterización de la diferencia lógica entre un mundo humano y otro, el mundo animal, se desdibuja y, en consecuencia, la especificidad de lo humano queda sin mayores posibilidades de elucidación.

Frente a su pretensión para con los educadores, señala: 
En efecto, más que una ampliación de su horizonte teórico, quizás brindar indicaciones prácticas a las cuales ajustarse. Con seguridad querrán saber qué recursos pedagógicos son los más recomendables y cuáles deben evitarse estrictamente si no se quiere poner en peligro todo el desarrollo del niño, pero, ante todo, y hablando en términos generales, si en principio conviene educar más o educar menos de lo que hasta ahora se ha venido haciendo. (pp. 70-71).

Así, propone una perspectiva de formación de educadores en donde imagina que no les es de suyo asumir distinciones entre el estatuto de la conceptualización, por un lado, y las posibles aplicaciones, por otro. Este marco invisibiliza, también, otra de las discusiones propias de los procesos dedicados a la formación de educadores: la pregunta por la transmisión de un saber. Presenta, en consecuencia, una serie de "indicaciones prácticas a las cuales ajustarse”, recursos pedagógicos recomendables: tal vez un deber hacer para la práctica pedagógica, lugar común hoy en algunos procesos tendientes a la formación del magisterio.

En el cuarto capítulo de su libro Introducción al psicoanálisis para educadores, titulado "Relaciones entre el psicoanálisis y la pedagogía”, Anna Freud dedica sus esfuerzos a presentar a los educadores lo que, a su juicio, serían tres puntos de vista propios del psicoanálisis y, en consecuencia, aquellos que se constituirían en aspectos orientadores de la práctica de los educadores. El primero es una división cronológica por la que transcurriría la vida del niño: "en tres periodos: la temprana infancia, que abarca hasta aproximadamente el quinto año de vida; un período de latencia, hasta los 11 o 13 años -el comienzo de la llamada pubertad-y, a su término, advendría, como fin, la adultez". Periodos presentados como "rasgos normales característicos a determinada actitud afectiva del niño frente a los seres de su ambiente y a determinada fase de su evolución instintiva”.

El segundo y el tercero de sus puntos de vista están referidos a la "estructura interna de la personalidad infantil”. Señala que los maestros imaginan y, por lo tanto, asumen la creencia asociada

[...] al niño sobre el cual deben actuar como unos seres unitarios y homogéneos, no atinando, por consiguiente a explicarse el carácter antagónico de su conducta, la discrepancia entre su querer y su poder y la disparidad entre sus propósitos y sus actos.

Presenta, en consecuencia, una estructura psíquica tripartita de la naturaleza infantil: la vida instintiva, el yo y el superyó (heredero de sus relaciones paterno-filiales).
Precisamente, el tercero de sus puntos de vista se refiere a la dinámica de las relaciones entre los sectores de la estructura psíquica tripartita, aspecto que contribuye a delinear una explicación sobre el comportamiento infantil. Dicha estructura psíquica -explicano operaría en el marco de "pacíficas instancias, sino estaría configurado por fuerzas en pugna", en donde

[...] la solución de cada uno estos duelos personales -verbigracia, entre el yo infantily un deseo instintivo inconveniente-dependerá de la fuerza relativa de las distintas pulsiones, es decir, de la cantidad de libido a disposición del deseo instintivo, en comparación con la energía de la tendencia opuesta, o sea, de la represión estimulada por el superyó. (p. 70).

Fuerzas denominadas pulsiones operarían en el marco de esa idea que nos presenta como estructura psíquica tripartita.

Como es posible entrever, Anna Freud presenta a los profesores una sofisticada discusión en donde, además -dice-, entran en juego conceptos y sus relaciones: libido, energía de la tendencia opuesta, represión, superyó. Discusión proveniente de la elaboración teórica que el psicoanálisis construye para explicar la condición humana y, como toda elaboración teórica, funciona en la medida en que se consideren como un todo sus elementos que, valga decir, no son tomados de la evidencia, ni de las certezas que provendrían del mundo que se nos aparece a los sentidos. En el marco del horizonte de lo inteligible, sustraer algunos elementos de las relaciones internas y presentarlos de manera aislada descontextualiza, desdibuja la misma idea de conceptualización, ya que cada concepto mantiene con los restantes la unidad teórica. Entonces, el horizonte dado por la unidad teórica configura uno de los aspectos capitales a la discusión pedagógica, pero no el único; los límites y las posibilidades de la transmisión de dicha unidad teórica son motivo de interrogación, también, para la discusión pedagógica.

Anna Freud, como es posible comprender, no solo se enfrenta a los problemas señalados: los asuntos relacionados con la teoría y el reto de establecer su posible aplicación; con su esfuerzo ante los profesores también hace frente a los avatares, a las dificultades propias con las que se encuentra quien desee transmitir un saber. Asunto de importancia también para el psicoanálisis y del cual no encontramos rastros en estas conferencias.

\section{La perspectiva desarrollista}

Al interrogar la lógica del desarrollo, desde la perspectiva del psicoanálisis, se discute la labor específica 
del maestro como depositario de una autoridad que se visibiliza en el aula -impelido a actuar allí.

Anna Freud presenta en su discusión una idea de maduración, en la cual se diferencian tres fases o períodos secuenciales -manera de entender la infancia que se hallaba en boga-: la temprana infancia, aproximadamente hasta los 5 años; luego, un período de latencia, el comienzo de la llamada pubertad, hasta los 11 o 13 años $y$, a su término, la adultez como destino, como fin. A cada una de estas fases le corresponde determinada actitud afectiva, con sus respectivos retrocesos o detenciones, consideradas como anormalidad y patología, aspectos propios de esta manera de abordar la discusión. Señala que existe correspondencia entre cierta fase del desarrollo individual y la escuela, con sus propósitos.

\begin{abstract}
Las fases evolutivas, que en su viaje hacia una meta bien determinada debe el niño atravesar, son otras tantas estaciones. Si una de estas etapas se le presenta con carácter muy seductor, surge la amenaza de que el niño comience a instalarse en ella permanentemente, negándose a proseguir su viaje, su futura evolución. (pp. 44-45).
\end{abstract}

Anna Freud presenta puntos de vista acerca del psicoanálisis simplificados con respecto a un esfuerzo de teorización que imagina, además, transmitir directamente en el proceso de formación de profesores y ellos -los profesores- a su vez, querrían aplicarlos en el escenario de su práctica pedagógica. Propone, con su trabajo, brindar a los maestros "ayuda y asistencia en su labor pedagógica".

La novedad introducida por el descubrimiento freudiano no fue ajena, en consecuencia, a algunos efectos en la circulación de sus ideas. El sentido común tradujo la idea del carácter determinante de los primeros años de vida a una más de las etapas del desarrollo humano; contribuyó a la circulación de cierta idea de maduración, atada a la cronología. Anna Freud no escapó a esta manera de abordar la discusión, al no hacer distinción entre el cuidado que requiere el niño (alimentación, aseo, abrigo, por ejemplo), en el marco de un paulatino desarrollo de las condiciones físicas y aquella otra discusión tendiente a elucidar la condición humana, su propia especificidad y, en este preciso marco, un proceso de comprensión del funcionamiento de su aparato psíquico, no obstante, claro está, su esfuerzo por distinguir entre la especificidad de lo humano (pulsional) y el mundo animal (instintual): sendos procesos anclados en un específico vínculo con el mundo.

Justamente, en los albores del denominado siglo del niño el psicoanálisis entra en el debate sobre el estatuto de lo humano. Sin embargo, su perspectiva se impregna de términos como maduración, evolución, etapas, fases o estadios del desarrollo humano: "eslabones naturales y normales de una predeterminada cadena evolutiva". Si bien la infancia se concibió como una invención social, ya que no siempre ha estado allí, Anna Freud con su discusión contribuyó a presentarla en términos de carencia, desvalimiento, latencia, en fin, en el marco del desarrollo: signos de época.

Por ello, es necesario repensar la perspectiva del desarrollo. Miller (2015) señala seis razones para ello. Implica, primero, un progreso finalizado; es decir, desde la perspectiva del desarrollo se da por sentado que el tiempo pasa y que el individuo debe llegar, o llegará, a un fin único. La idea de un antes y un después se impone. Segundo, supone una trayectoria normalizada, típica, es decir, una predeterminación a lo que podríamos llamar programación, algún fin preestablecido. Tercero, supone la noción de una ampliación: del menos al más. Cuarto, nos hace pensar en términos de detenciones y déficit, vía por la que se cuela la idea de normalización y patología. Quinto, supone la existencia, de estadios, lo cual se traduce, seis, siempre en el dominio de un ideal (p. 34).

En pocas palabras, interrogar la idea de maduración nos permite vislumbrar, primero, que no todos los involucrados en el proceso de escolarización lo abordan de la misma manera. Segundo, si bien es cierto que el aparato educativo está organizado de manera secuencial, con arreglo a ciertos propósitos y determinados fines, esto no implica que la condición humana opere con arreglo a estos propósitos. Es preciso interrogar la condición humana y, en ella, la función de los procesos educativos.

Así, al interrogar la lógica del desarrollo no logramos olvidar, de hecho, que trabajamos con sujetos, que requieren de nuestro cuidado y que, además, en el marco de una estructural dependencia de otras personas, algo acaece, algo pasa, pero que, en todo caso, no se trata de un simple proceso de maduración, ya que el mismo proceso incluye al sujeto y genera condiciones de posibilidad para que algo acaezca en su aparato psíquico. Para Sigmund Freud, si "los hombres supieran aprender de la observación directa de los niños estos tres ensayos podrían no haberse escrito". Hace falta, para saber, "paciencia y la destreza", concluye Freud (1905).

\section{Desarrollo versus estructura}

En Sigmund Freud, la idea de aparato psíquico no remite a la discusión neurológica (de la cual fue insigne representante). No es un lugar espacial, ni anatómico; es un espectro especial del cual podemos saber por ciertos efectos, por sus manifestaciones, por sus 
huellas: sueños, olvidos, inhibiciones, resistencias, preferencias y esfuerzos, tropiezos, resistencia de los síntomas, angustias... en pocas palabras, por aquello que se quiere y no va, por ese malestar, por aquello que falla. La condición humana estaría dada, en consecuencia, por la singular y paradójica manera como operaría su aparato psíquico.

Si bien sus acercamientos a la pregunta por la infancia desde 1905 partían de ciertas premisas fisiológicas y químicas, paso a paso va organizando su conceptualización en tono analítico; sometiendo a examen los poderes represores (el asco y la moral) organiza su discusión en torno a unas imposiciones teóricas que configuran así un sistema de coacciones abstractas que, poco a poco, ordenaron la base de la teoría analítica: el psicoanálisis (Millot, 1979). Su piedra angular, la sospecha de que la infancia también está sometida a poderosas fuerzas, lo llevó a advertir que en los niños más pequeños operan normalmente impulsos sexuales sin ninguna necesidad de estimulación externa. Controvierte con ello el supuesto común -inclusive en nuestros días- de que en la infancia este tipo de mociones pulsionales no están presentes. Sigmund Freud destaca, más allá de la discusión moralista, que lo importante son los efectos producidos por tales experiencias debido a su función en la organización del aparato psíquico que, entre tanto, ha tenido lugar. En su escrito Tres ensayos de teoría sexual (1905) precisa que es una premisa necesaria que "no deja de contener más que lo que el psicoanálisis necesita suponer o permite comprobar".

Ante la pregunta por la infancia -en boga para la moderna psicología y la discusión de los pedagogos desde las últimas décadas del siglo XIX-, imaginándola como periodo de incompletud, preparatoria para la vida adulta, Anna Freud contribuye, no obstante, a destacar que un olvido es constitutivo de lo humano: pese al esfuerzo no logramos recordar nuestros primeros años.

No logramos iluminar los primeros años de nuestra vida ni reunir una serie ininterrumpida de recuerdos pertenecientes a dicha época. En todos los casos nos será dable hilvanar las vivencias hasta determinado momento, que es muy distinto para cada persona: en algunas el quinto año de vida, en tanto que en otras el límite se fija en el cuarto y aun en el tercero. Pero, más allá, todos tenemos una inmensa laguna, un periodo de tinieblas en el que sólo pueden distinguirse los contornos de recuerdos fragmentarios, aislados de su contexto y que considerados detenidamente parecen faltos de sentido e importancia. Nadie dejará de advertir que enfrentamos una extraña contradicción de hechos objetivos. Por una parte, la observación directa del niño pequeño y la descripción de la propia infancia que recogemos de nuestros familiares, nos han enseñado que el niño se comporta de manera inteligente y vivaz; que manifiesta preferencias y aversiones, y que en múltiples e importantes aspectos actúa como un ser muy sensato. Por otro lado, esa misma época se ha extinguido para la memoria, dejando tan sólo rastros escasos e incompletos. Mas, según el referido testimonio de todo maestro, al cabo de este primer periodo, el ser humano ya entra en la vida como un pequeño individuo plenamente desarrollado y provisto de personalidad propia. (p. 20).

En la dirección marcada por Sigmund Freud, ante la pregunta por la infancia, Anna señala que, como un efecto del enigmático proceso de humanización se produce un particular rasgo, constitutivo, a su vez, en cada individuo de su singular entrada en el mundo humano: un olvido, un no acceso a ciertos contenidos que se manifiesta como la no disposición en el plano consciente de recuerdos de nuestros primeros años de vida; fenómeno que se constituyó en un asunto relevante para el trabajo de elucidación iniciado por el psicoanálisis.

En este marco, ¿cómo explicar ese olvido?, ¿cuáles fuerzas provocan esa represión de las impresiones infantiles?, ¿cómo comprender esta dinámica entre olvido y conciencia? La indagación desde el psicoanálisis se abocó a esta tarea: "no se olvida nada sin que se tengan buenos -pero casi siempre desconocidos- motivos para olvidar" (Anna Freud, 1930, p. 21).

Las tinieblas en que se halla sumido el primer periodo de la vida, y los obstáculos que resisten todo intento de iluminación hicieron sospechar al psicoanálisis que allí debía cubrirse algo muy importante. Ante un cofre de cerrojo sobremanera complejo y difícil de forzar, el ladrón deduce que sus esfuerzos no habrán de ser vanos, pues nadie se molestaría en proteger tanto una cosa de magro valor. (p. 22).

La discusión, precisamente sobre la dinámica consciente-inconsciente, aprehendida en un nuevo dispositivo de práctica clínica, tal como Sigmund Freud lo precisó y que le llevó a formular una teoría, no está presente en esta discusión que Anna presenta a nombre del psicoanálisis. Mientras a Sigmund Freud su trabajo le implicó una doble ruptura: por un lado, con la manera como usualmente se abordaban las discusiones sobre la clínica de las afecciones emocionales y, por otro, una ruptura epistemológica, que lo llevó a distinguir de los fenómenos la posibilidad de inteligibilidad, la discusión propuesta en este texto por Anna Freud solo presenta manifestaciones del acaecer psíquico.

Para Sigmund Freud el concepto de lo inconsciente se le hizo necesario. Con él le fue posible dotar de 
sentido y coherencia cosas que antes no lo tenían, pues gran parte de la actividad psíquica del sujeto (sueños, olvidos, inhibiciones, operaciones fallidas, lapsus) le resultaba incomprensible y oscura; con el desciframiento de estos indicios, mediante el concepto de lo inconsciente, le fue posible descifrar, también, el mismo andamiaje del funcionamiento de la cultura: los chistes, el arte, la angustia, también, el malestar humano con la misma cultura. El concepto de lo inconsciente le posibilitó conectar y comprender que algo más allá de la conciencia opera en nosotros; que, en el proceso de comprensión de lo humano, era necesario colocar una instancia psíquica que operara al lado de la conciencia. Lo que Freud plantea es que el sujeto no conoce su propia condición, que se le escapa su propio saber sobre sí mismo. En pocas palabras, sin operar sobre la base de la razón y de la conciencia un nuevo sujeto es presentado por el psicoanálisis: al reconocer lo inconsciente como una parte del sistema psíquico que se manifiesta sobre el sujeto, que tiene efectos sobre su conducta, que, en definitiva, también define su ser.

En consecuencia, lo inconsciente se define, primero, como una instancia del sistema psíquico que contiene representaciones que comparten la propiedad de haber sido reprimidas: no sabemos de ello. Segundo, que opera en el marco de ciertas propiedades que no se relacionan en función del tiempo, ni de la razón, ni de la realidad exterior, sino que sus contenidos están relacionados en función de la propia dinámica psíquica de cada sujeto. Mientras que la conciencia se relaciona con la realidad exterior, con las percepciones que se obtienen del mundo externo, lo inconsciente no se centra en la existencia de la realidad externa. Como ya se dijo, de lo inconsciente sabemos por medio de sus formaciones (sueños, olvidos, operaciones fallidas, lapsus, malestar, inhibiciones, síntomas): el sujeto puede enterarse de algunas de sus manifestaciones; no son construcciones claras, ni evidentes, sino que surgen, aparecen por sorpresa y sobrepasan al sujeto que piensa conscientemente; adquieren valor cuando nos preguntamos por ello.

Anna Freud destaca que "es evidente que la formación del ser humano concluye antes de lo que generalmente se sospecha" (p. 18) y, añade, "según el referido testimonio de todo maestro, alcaldes del primer periodo, que el ser humano ya entra en la vida escolar como un pequeño individuo plenamente desarrollado y provisto de personalidad propia" (p. 21). $\mathrm{Al}$ interpelar a los profesores, destaca ciertos rasgos que no logra conceptualizar y, sin embargo, apuntan a la especificidad de lo humano:

Al menos en sus primeros contactos con un niño, el maestro no tardará en advertir que éste en modo alguno reacciona ante su personalidad y actitud reales, sino que ya trae consigo determinadas posturas o modalidades anteriormente fijadas y establecidas, y que le opone la desconfianza, la terquedad o la hostilidad que adquirió en sus experiencias previas con otros adultos. (p. 17).

En sus conferencias se cuela, además, un debate que a lo largo del siglo xx se aupó: el asunto del límite. Cuando dice: "si en principio conviene educar más o educar menos de lo que hasta ahora se ha venido haciendo", coloca el acento en la discusión sobre ciertos efectos no deseados, que podrían aparecer en los sujetos; síntomas que determinados procesos de educación podrían o no producir. Comparte la idea relacionada con "encontrar" y promover determinados procesos educativos, adecuados, en todo caso, a la condición de la infancia "si no se quiere poner en peligro todo el desarrollo del niño".

Precisamente, algunos educadores cuestionan la idea de coerción como algo que se debe evitar en las prácticas educativas. Inspirados en la circulación de las discusiones provenientes del psicoanálisis, formulan proyectos pedagógicos cuyo horizonte se configuró alrededor de principios basados en las mínimas restricciones posibles; principios pedagógicos que, en el propicio marco político de visibilización hacia el niño, contribuyen a materializar un ideal pedagógico caracterizado por la libertad y la autonomía ${ }^{1}$, cuyos efectos estamos comprendiendo ahora.

1 La discusión propuesta desde el psicoanálisis repercutió de manera considerable sobre los debates realizados a propósito de los procesos educativos. El pensamiento pedagógico del siglo xx recogió las polémicas que suscitó. En algunos casos produjo un visceral rechazo a sus planteamientos, en otros pocos, deseo de comprender sus postulados y, para algunos más, grandes esperanzas que contribuyeron a nutrir esfuerzos en la organización de escenarios escolares con ciertas especificidades que, como común denominador, se propusieron llamar progresistas. Dada la complejidad de lo que está en juego, aquellos planteamientos del psicoanálisis que contribuyeron a generar una variedad de experiencias relacionadas con la educación se caracterizan por la dispersión de su horizonte: por un lado están los esfuerzos tendientes hacia la posibilidad de generar espacios para trabajar con niños que presentan ciertas dificultades en el aprendizaje; por otro, aquellos que se orientan hacia la generación de espacios para trabajar con ciertas patologías (autismo, psicosis, por ejemplo); a su vez, otros trabajan en la construcción de escenarios pedagógicos 'propicios', es decir con la idea de profilaxis, individual o social. Baste, por ahora, señalar algunos que fueron organizados rápidamente a la aparición del psicoanálisis: Maud Mannoni (1923 - 1998) quien, hacia finales de la década de los 60, fundó en Francia, junto con Robert Lefort y Rose Marie e Yves Guerin, la Escuela Experimental de Bonneuil, dedicada a lograr una estructura institucional que posibilitase trabajar pedagógica y clínicamente con niños que no lograban escolarizarse ya que las instituciones no ofrecían respuestas a su singularidad. Alexander Sutherland Neill (1883-1973) fundó en el sur de Inglaterra la escuela de Summerhill, cuyos presupuestos apuntan a configurar espacios de no represión social. Vera Schmidt (1889-1937) organizó el Laboratorio-Hogar 
No obstante, si bien es cierto que es loable este horizonte político, los desarrollos conceptuales elaborados desde el psicoanálisis contribuyen a discutirlo cuando de procesos de educación y de escolarización se trata. Tales desarrollos permiten, además, entrever sus efectos, tanto pedagógicos como sociales. La dinámica psíquica humana opera con presupuestos paradójicos. El esfuerzo del psicoanálisis, precisamente, no solo contribuye a centrar la atención en el plano político, también posibilita discutir, sobre todo, la misma práctica pedagógica y, en ella, el vital esfuerzo de conceptualización de la particularidad de la condición humana, destacando, en el marco de la singularidad de los sujetos inmiscuidos en procesos de formación, la arista de los efectos producidos en el marco del funcionamiento del aparato educativo.

Si los niños no llegan a la escuela como tabula rasa, maleables y dispuestos para el trabajo con el profesor, entonces, las manifestaciones de preferencias, sus dificultades, inhibiciones serían singulares modalidades asociadas a la satisfacción. En este preciso punto Anna Freud señala que no repasará el camino recorrido por el psicoanálisis: "la descripción del método psicoanalítico traspasaría esta obra". No arriesga, en consecuencia, una presentación y, por ende, una discusión al respecto, señala que "sólo adelantaremos que cumplió esta tarea mediante la interpretación de los mencionados actos fallidos y de los sueños de sujetos sanos, así como a través de la interpretación y curación de los síntomas psicopáticos". Esgrime que "lo que más nos interesa aquí son los hechos y vivencias de los primeros años de la infancia [...]" (p. 22). Interesante confesión que permite interrogarnos por tres aspectos constitutivos, precisamente, de su discusión en torno a las relaciones entre el psicoanálisis y la pedagogía: el psicoanálisis como discusión teórica acerca del estatuto humano, su método (la clínica) y, en este marco, aspectos relacionados con la pedagogía, específicamente en aquellos relacionados con la formación de profesores: el problema del saber, el reto que encarnan los procesos de transmisión de un saber y aquellas dificultades o inhibiciones con las que nos deparamos frente al problema del saber.

En este preciso instante de su discusión, echamos en falta su elaboración conceptual; no esboza los principios teóricos de los que en ese momento disponía el psicoanálisis y su investigación. En 1905, Sigmund Freud, sabedor de la distinción entre el sentido común y la investigación, manifestó que "la afirmación de que en la infancia falta la pulsión sexual, que sólo se despierta en la pubertad, forma parte de la opinión

de Moscú entre 1921 y 1924 bajo la tentativa de generar una experiencia educativa libre de ciertos confinamientos sociales. popular" (p. 157). Distinción que le permite esbozar, también, que existiría una relación entre saber y pulsión. La inhibición intelectual, el no querer saber se convierte en "el principal culpable de nuestra ignorancia acerca de las bases de nuestra vida".

Con todo, Anna Freud participa del debate por una reforma de la educación; plantea la pregunta por las maneras adecuadas de educar; discute en torno a determinadas prácticas pedagógicas, cuyo horizonte es el no deseado escenario de "poner en peligro todo el desarrollo del niño" y, en consecuencia, promulga que otras prácticas pedagógicas deberían advenir. Sin embargo, parece no estar inserta en la discusión de la que dice formar parte. Al preguntarse por maneras adecuadas de educar olvida que sería necesario discutir, primero, el estatuto de lo humano y, allí, cómo advendrían los propósitos.

Reconoce, en todo caso, que su discusión sobre la pedagogía está en el marco de una pugna por el significado, es decir, sobre el cómo interpretar ciertos hechos; señala, además, que

[...] todas las corrientes de la psicología se han dejado engañar por una falsa apariencia, pues al aceptar como único material de su investigación científica aquella parte del alma humana conocida por uno mismo, en razón de que el sujeto ignora los primeros años infantiles, forzosamente incurrirá en grave menosprecio de su significado. (1930, p. 21).

Sabemos, por el trabajo de Sigmund Freud, que para el psicoanálisis, el valor de los conceptos reside en que proceden de un particular procesamiento del acaecer psíquico. Procesamiento que al ser traducido en formato de supuestos que son puestos a prueba en la práctica clínica pueden ser o no abandonados, si el trabajo con ellos en la práctica clínica así lo sugiere. Se convierten, es posible decir, en intentos de dar razón al suceder psíquico. La teoría analítica se nutre de esas elaboraciones, no las olvida y, por el contrario, se mantiene siempre en contacto con los fundamentos, no se aleja de ellos. Es necesaria, en consecuencia, cierta vigilancia al respecto. Procesamiento y supuestos son expresiones que buscan dar cuenta de un proceder que denominamos actividad científica (Miller, 1987).

Así, el esfuerzo de Sigmund Freud no es una manera de proceder exclusiva del psicoanálisis; este se puede considerar como manifestación del espíritu de la ciencia, en un ámbito especialmente difícil a la captación conceptual de la ciencia (Miller, 2015, p. 156). Este marco hace posible pensar que los fenómenos que aparecen como paradójicos al sentido común, puedan llegar a comprenderse desde uno de los campos, aquel que precisamente se organiza alrededor del saber y sus procedimientos: la ciencia que es efecto de ello. 
En consecuencia, existe diferencia entre el uso de referencias provenientes del psicoanálisis o estar a la altura de su discusión. Por su trabajo, distinguimos a Sigmund de Anna Freud, pese a los esfuerzos realizados y a la labor desplegada a nombre del psicoanálisis.

Con todo, su esfuerzo es significativo para el periodo en el cual trabajó. Anna Freud contribuyó a poner en discusión cierta sospecha que por siglos hemos acarreado. Además, su debate posibilita, primero, reconocer la delicada labor que realizan los maestros; segundo, cuestiona el sentido común al indicar que los niños llegan a la escuela hechos, completos "seres humanos": cada uno de ellos reacciona de cierta manera y en su conducta es posible reconocer: prevenciones y temores, inhibiciones, preferencias y repulsión, celos y cariño, afecto y hostilidad.

Si nos dirigimos a la jardinera quien -según lo dicho- debería disfrutar la envidiable situación de cultivar en terreno todavía virgen, con gran asombro la veremos quejarse de que los pequeños de tres a seis años a su cargo, son ya verdaderos "seres humanos". Traen consigo un enorme cúmulo de cualidades personales y reaccionan de una manera particular ante su conducta, al punto de que en cada uno de ellos es fácil reconocer ciertas prevenciones y temores, preferencias y repulsión, formas especiales de celos y de cariño, búsqueda de afecto y hostilidad. Ni cabe pensar siquiera en la posibilidad de que ella imponga su sello personal a un ser todavía informe. Muy al contrario, encuéntrase rodeada de una multitud de complejas personalidades en miniatura, extraordinariamente difíciles de modificar. (pp. 17-18).

Anna Freud se interroga por la complejidad del escenario escolar, por el cúmulo de asuntos que convergen en él. Controvierte la idea común relacionada con la infancia como periodo de la vida diferente del adulto al preguntarse por su especificidad; contribuye, con su trabajo, a enmarcarla en su vínculo con la escuela. En consecuencia con su razonamiento, abre la posibilidad de una serie de preguntas: ¿En qué radicaría la diferencia si supone un sujeto en pleno funcionamiento? ¿Cuál sería la particularidad de este momento de la vida? Si destaca que en la escuela convergen "una multitud de complejas personalidades en miniatura, extraordinariamente difíciles de modificar", cuál sería la función de la escuela y la especificidad del acto educativo dadas estas dos ideas: (1) conformados, incluso antes de los tres años; y (2) difíciles de modificar.

No logra con su esfuerzo, sin embargo, elaboraciones posibles al respecto. Su discusión, al estar centrada en la lógica de la maduración, no intenta responder la pregunta por la subjetivación. Describe, in extenso, comportamientos característicos en los niños y que la educación se empeña en sofocar, en domeñar.

Solo las personas que están obligadas al trato constante con el niño desde la lactancia hasta el quinto año de vida podrán describirlas con fidelidad. Interrogadas al respecto, responden lo siguiente: el niño es insoportablemente inescrupuloso y egoísta; no le preocupa sino imponer su propia voluntad y satisfacer sus deseos; le es en absoluto indiferente que otros sufran o no por ello. Es sucioy repugnante; no vacila en tocar y aún en llevar a la boca las cosas nauseabundas. Es desvergonzado con su propio cuerpo, y todo cuanto los demás tratan de ocultar a su vista, despierta su curiosidad. Es voraz y bulloso. Es cruel con todos los seres vivos más débiles que él, y lo impulsa un afán de destruir todo objeto inerte. Tiene multitud de vicios corporales: se chupa los dedos, se muerde las uñas, se hurga la nariz, juega con los órganos genitales. Se dedica a todas estas actividades con el mayor apasionamiento, exige imperiosamente la gratificación de todos sus deseos y le resulta intolerable la menor demora. En las descripciones de los padres, dos quejas ocupan invariablemente el plano principal. En primer lugar, su sentimiento de absoluta impotencia: apenas se le ha quitado una mala costumbre, cuando ya otra aparece en su lugar. Luego, la desolada pregunta acerca del origen de todo ello, ya que, por cierto, esos modales no los ha copiado de los padres y en lo que hace a las malas compañías, se ha tratado muy especialmente de mantenerlo alejado de ellas. (pp. 36-37).

Anna Freud presenta la problemática que le depara a la escuela. Convergen -nos dice- en ese escenario un variado conjunto de personalidades en miniatura, por un lado, pero además, difíciles de modificar. Agrega,

Es sabido que durante la entera evolución descrita, el niño se conduce como si para él no existiese nada más importante que aprovechar sus fuentes placenteras e imponer sus deseos. Por el contrario, en la actitud adoptada por la educación se hallaría como su finalidad más significativa la de impedir tales designios infantiles. Esto suscita una incesante guerra en miniatura entre la educación y el niño. Aquella quiere sustituir el placer de la suciedad por la repugnancia, el impudor por la vergüenza, la crueldad por la compasión, el afán destructivo por el respeto hacia los objetos. La curiosidad y las maniobras en el propio cuerpo han de eliminarse mediante prohibiciones, la inescrupulosidad trocarse en consideración, el egoísmo, en altruismo. Paso a paso, la educación persigue justo lo contrario de lo que el niño quiere, y en todo momento conceptúa como lo más conveniente lo diametralmente opuesto a los impulsos instintivos del niño. Según hemos visto, la prosecución del placer es, para éste, la finalidad cardinal de su vida; el adulto, 
en cambio, pretende habituarlo a conceder mayor importancia a las demandas del mundo externo que las exigencias instintivas internas. El niño es impaciente, no tolera dilaciones y sólo se esfuerza por algo presente; el adulto quiere enseñarle a diferir la gratificación de sus instintos y a precaverse con vistas al futuro. (pp. 42-43)

Incesante guerra en miniatura entre la educación y el niño que revela el escenario humano por excelencia. Con el niño civilizado, continúa argumentando para nosotros Sigmund Freud (1913), "se tiene la impresión de que el establecimiento de esos diques es obra de la educación, y sin duda alguna ella contribuye en mucho". Indicación que invita a examinar la perspectiva que contribuye a explorar las relaciones posibles entre la dimensión sincrónica (estructural) y la diacrónica (histórica, contextual e institucional) y en ellas la función de la escuela. Con su reflexión, apunta a la posibilidad de pensar que la labor de la formación que se desarrolla en la escuela depende más de la especificidad del proceso de conformación del sujeto y menos de los propósitos con los cuales están hechas las mismas instituciones, lo cual nos pone frente a la exigencia de concebir una dimensión estructural en la educación. Más aún si convertimos en pregunta la siguiente afirmación de Anna Freud: "la educación de un niño comienza con su primer día de vida" (p. 29). Entonces, ¿cómo concebir la escolarización si su educación comenzó desde el primer día de vida?

\section{A modo de cierre}

La investigación inaugurada por Sigmund Freud marca la posibilidad de discutir la dimensión estructural que está en juego en el marco de los procesos educativos. Contrariando el vector de la comprensión hasta ese momento imperante, coloca el interrogante sobre el sujeto: Sigmund Freud se pregunta por su estatuto, su proceso de estructuración, así como por la cultura y los vínculos que proporciona. La idea, común en el siglo XIX, referida a que la formación depende de la escuela, con este gesto analítico queda definitivamente tensionada. Un más allá de la variabilidad histórica y contextual interroga: el aparato escolar no se hace enteramente con arreglo a propósitos, a intenciones, a fines; sus alcances no solo se relacionan con los objetivos políticos que traza cada época y que, en su horizonte de funcionamiento, recogen las instituciones.

Ahora bien, en el marco de la pregunta por la función de la escuela, cabe interrogarse, también, por la postura de Sigmund Freud, aquella que le posibilitó indagar por algo estructural del lado del sujeto; máxime cuando señaló, además, que el ejercicio de la facultad del pensamiento está íntimamente ligado al destino de las pulsiones parciales (1905).

\section{Referencias}

Bustamante, G. (2013). Sujeto, sentido y formación. La educación vista desde el psicoanálisis, con sesgo lingüístico. Editorial San Pablo, Doctorado Interinstitucional en Educación (DIE). Bogotá: Universidad Pedagógica Nacional.

Bustamante, G.; Rodríguez, C.; Díaz, C.; Carvajal, G.; Moreno, S.; Flórez, R. y Domínguez, J. (Inédito). El concepto de campo (a propósito de las tesis de unos estudiantes). Bogotá: Universidad Pedagógica Nacional.

Díaz-Soler, C. (2015). El debate en torno a la condición humana: Sigmund Freud y su investigación (1895-1900). En: Pensadores imprescindibles para leer el poder hoy. Bogotá: Fondo Editorial de la Universidad Distrital Francisco José de Caldas.

Freud, A. (1930/1948). Introducción al psicoanálisis para educadores. Buenos Aires: Paidós.

Freud, S. (1905/1990). Tres ensayos de teoría sexual. En Obras completas (vol. 7). Buenos Aires: Amorrortu.

Freud, S. (1913/1990). Introducción a Oskar Pfister, El método psicoanalítico. En: Obras completas (vol. 12). Buenos Aires: Amorrortu.

Freud, S. (1915). Ensayos sobre metapsicología. En: Obras completas (vol. 14). Buenos Aires: Amorrortu.

Freud, S. (1915/1990). Pulsiones y destinos de pulsión. En: Obras completas (vol. 14). Buenos Aires: Amorrortu.

Freud, S. (1925). Presentación autobiográfica. Amorrortu.

Freud, S. (1929/1990). Malestar en la cultura. En: Obras completas (vol. 21). Buenos Aires: Amorrortu.

Freud, S. (1932/1990). Conferencia 34. En: Nuevas conferencias de introducción al psicoanálisis. En: Obras completas (vol. 22). Buenos Aires: Amorrortu.

Lajonquière, L. de. (1999). Infancia e ilusión (psico) pedagógica. Escritos de psicoanálisis y educación. Buenos Aires: Nueva Visión.

Lajonquière, L. de. (2011). Figuras de lo infantil. Buenos Aires: Nueva Visión.

Miller, J. (1988). Freud y la teoría de la cultura. En: Elucidación de Lacan. Buenos Aires: Paidós.

Miller, J. (1989). Cómo se inventan nuevos conceptos en psicoanálisis. En: Introducción a la clínica lacaniana. Conferencias en España. Barcelona: ELP- RBA. 
Miller, J. (2015). Elementos de epistemología. En: Seminarios en Caracas y Bogotá. Buenos Aires: Paidós.

Millot, C. (1979). Freud antipedagogo. Barcelona, Paidós (1982).
Saldarriaga, Ó. (2000). Matrices éticas y tecnologías de formación de la subjetividad en la pedagogía colombiana, siglos XIX y XX. Pretextos Pedagógicos, 9. 